\title{
KNIFE CUTS OF ENTORHINAL CORTEX: EFFECTS ON DEVELOPMENT OF AMYGDALOID KINDLING AND SEIZURE- INDUCED DECREASE OF MUSCARINIC CHOLINERGIC RECEPTORS ${ }^{1}$
}

\author{
DANIEL D. SAVAGE, LEWIS C. RIGSBEE, AND JAMES O. MCNAMARA*,2 \\ Departments of Medicine (Neurology) and Pharmacology, Duke University Medical Center, and *Epilepsy Research Laboratory, \\ Veterans Administration Medical Center, Durham, North Carolina 27705
}

Keceived February 21, 1984; Revised August 15, 1984; Accepted August 16, 1984

\begin{abstract}
This report examines the effect of transection of the entorhinal hippocampal projection on amygdaloid kindling. We found that: (1) bilateral knife cuts of entorhinal cortex but not of dorsal neocortex antagonize the development of amygdaloid kindling; and (2) bilateral knife cuts of entorhinal cortex eliminate the seizureinduced decrease in number of muscarinic receptors of dentate granule cells. We suggest the following interpretations of these data: (1) the hippocampal formation circuitry facilitates the development of amygdaloid kindling; and (2) the decline of muscarinic receptors after kindled seizures is due to excessive activation of granule cells by axons from entorhinal cortex, a noncholinergic afferent.
\end{abstract}

Kindling, an animal model of temporal lobe epilepsy, is a phenomenon in which repeated administration of an initially subconvulsive electrical stimulus eventually results in intense limbic and generalized motor seizures (Goddard et al., 1969). Once established, the kindling effect is permanent. The cellular and molecular mechanisms responsible for this phenomenon are unknown.

We previously demonstrated transient reductions of the number of muscarinic cholinergic receptors in dentate granule cells of hippocampal formation following amygdaloid kindling (Dasheiff et al., 1981; Savage et al., 1983). This paper focuses on two questions related to this finding: (1) Does the hippocampal formation regulate the development of amygdaloid kindling? and (2) What is the mechanism responsible for the decline of muscarinic receptor number in this model? The principal excitatory afferent of the hippocampal formation arises from entorhinal cortex (Andersen et al., 1966). The immediate and principal target of this projection is the dentate granule cells (Hjorth-Simonsen and Jeune, 1972). To begin to address the questions posed, we examined the effects of transecting the entorhinal-hippocampal projection on the development of amygdaloid kindling and on the kindled seizure-induced decline of muscarinic receptors.

\section{Materials and Methods}

Animals. Adult male Sprague-Dawley rats (Charles River Breeding Laboratory, Boston, MA), initially weighing 225 to $250 \mathrm{gm}$, were used in all experiments.

Amygdaloid kindling. The methods for surgical placement of bipolar electrodes into the right amygdala and the subsequent kindling stimulation procedures were the same as described previously (McNamara,

${ }^{1}$ This work was supported by National Institutes of Health Grants NS 17771 and 2 T 32MH15177. We thank Ms. Eloise Pittman for her help in preparing the manuscript.

${ }^{2}$ To whom correspondence should be addressed.
1978; Dasheiff and McNamara, 1980). The stereotaxic coordinates for the electrode in the right amygdaloid complex were: $1.0 \mathrm{~mm}$ posterior to bregma, $4.8 \mathrm{~mm}$ right of sagittal suture, and $1.8 \mathrm{~mm}$ above the horizontal zero line (Pellegrino et al., 1979). Animals received five to seven stimulations per day at intervals of at least $90 \mathrm{~min}$. Animals were defined as kindled after exhibiting three class 4 or class 5 seizures (Racine, 1972) in which the rearing and/or loss of posture persisted for at least $20 \mathrm{sec}$. If kindling had not been established after 50 stimulations, no additional stimulations were administered, and the animal was arbitrarily designated as requiring 50 stimulations to kindle.

The afterdischarge thresholds were determined by recording the electroencephalogram from the bipolar electrode in the amygdala following each stimulation train. The current of the initial stimulus was $200 \mu \mathrm{A}$. If no afterdischarge was detected, the current of each subsequent train was increased by $100 \mu \mathrm{A}$ until an afterdischarge occurred. The interval between subsequent trains was approximately 30 sec.

Animals were killed by decapitation $24 \mathrm{hr}$ after kindling was completed. The brain was quickly removed, frozen in isopentane, chilled in a dry ice/methanol bath, and stored at $-70^{\circ} \mathrm{C}$. Electrode placements were determined from study of Nissl-stained frozen sections taken in the coronal plane. The placements were equivalent in the lesioned and unlesioned groups and resided in either the central, basolateral, or lateral posterior nuclei of the amygdala.

Knife cuts. Knife cuts were placed in the entorhinal cortex bilaterally at the time of electrode implantation in the experimental animals. The site of the knife cuts is depicted schematically in Figure 2. A Kopf stereotaxic knife was positioned $1.1 \mathrm{~mm}$ anterior to the transverse sinus and $3.5 \mathrm{~mm}$ lateral to the sagittal suture. With the knife blade retracted, the shaft was lowered to a point $1.0 \mathrm{~mm}$ below the dura. The knife blade was then extended laterally a distance of $3.0 \mathrm{~mm}$ from the shaft such that the blade was oriented in a plane perpendicular to the midline. A vertical cut was made by lowering the knife another $5.0 \mathrm{~mm}$. Holes were drilled in the skulls of controls, but the knife was not lowered.

Knife cuts were placed in neocortex bilaterally at the time of electrode implantation in an additional group of experimental animals. The stereotaxic knife was placed $1.0 \mathrm{~mm}$ posterior to bregma and 2.0 $\mathrm{mm}$ lateral to the sagittal suture. The knife blade was then extended laterally a distance of $3.0 \mathrm{~mm}$ from the shaft such that the blade was oriented in a plane perpendicular to the midline. A vertical cut was 
made by lowering the knife $1.5 \mathrm{~mm}$ below the cortical surface. Holes were drilled in the skulls of controls, but the knife was not lowered.

To verify the location of the knife cut, serial horizontal sections were taken through the posterior portion of the brain after coronal sections for electrode localization were completed. Analysis of Niss] stains of these sections (Fig. 1) demonstrated that the lesions were usually posterior to the angular bundle (Fig. 2) and extended to a depth corresponding to level IV of Hjorth-Simonsen and Jeune (1972), thereby sparing the ventral third of the hippocampal formation. A single experimental animal was deleted from the analyses because a lesion was identified only unilaterally rather than bilaterally.

In preliminary experiments, we examined the distribution of degeneration products (Fink and Heimer, 1967) in two animals sacrificed 5 days after a unilateral lesion similar to that portrayed in Figure 2. In accord with the detailed description of the subdivisions of entorhinal cortex (Steward, 1976), we found silver deposition reflecting degenerating terminals confined mainly to the middle third of the molecular layer of the dentate gyrus ipsilateral to the lesion. The outer third of the molecular layer was largely spared. The dorsoventral extent of the degeneration products in the dentate ranged from level II to level IV as described by Hjorth-Simonsen and Jeune (1972) and thus spared the ventral third of hippocampal formation. Degenerating terminals and fibers were also apparent in stratum lacunosum moleculare of Ammon's horn. We did not conduct these analyses in the standard experimental protocol because the degeneration products are no longer detectable 21 to 28 days after this lesion, when kindling has been completed.

In vitro radiohistochemistry of muscarinic cholinergic receptors. Muscarinic cholinergic receptors were measured with a quantitative radiohistochemical method using the (-)-stereoisomer of the radiolabeled antagonist, $\left[{ }^{3} \mathrm{H}\right]$ quinuclidinyl benzilate $\left(\left[{ }^{3} \mathrm{H}\right] \mathrm{QNB}\right)$. Previous studies from this laboratory (Savage et al., 1983) verified that binding to slidemounted sections exhibited properties similar to those of binding in membrane preparations. These experiments support the conclusion that $\left[{ }^{3} \mathrm{H}\right] \mathrm{QNB}$ is binding to muscarinic cholinergic receptors.

The present experiments were performed as previously described (Savage et al., 1983). Binding was performed in the presence of $0.3 \mathrm{nM}$ $\left[{ }^{3} \mathrm{H}\right] \mathrm{QNB}$ alone (Fig. 3) or with added $10^{-6} \mathrm{M}$ atropine. This concentration of $\left[{ }^{3} \mathrm{H}\right] \mathrm{QNB}$ results in occupancy of approximately $90 \%$ of muscarinic receptors under the conditions used. After incubation, slides were rinsed, dried, and apposed to ${ }^{3} \mathrm{H}$-sensitive film (Ultrofilm, LKB). The film was exposed for 10 days at $-20^{\circ} \mathrm{C}$. The film was then developed for $5 \mathrm{~min}$ in Kodak D-19 at $18^{\circ} \mathrm{C}$, rinsed, and fixed for $5 \mathrm{~min}$ in Kodak Rapid Fixer. The resulting $\left[{ }^{3} \mathrm{H}\right] \mathrm{QNB}$ autoradiographs of hippocampal

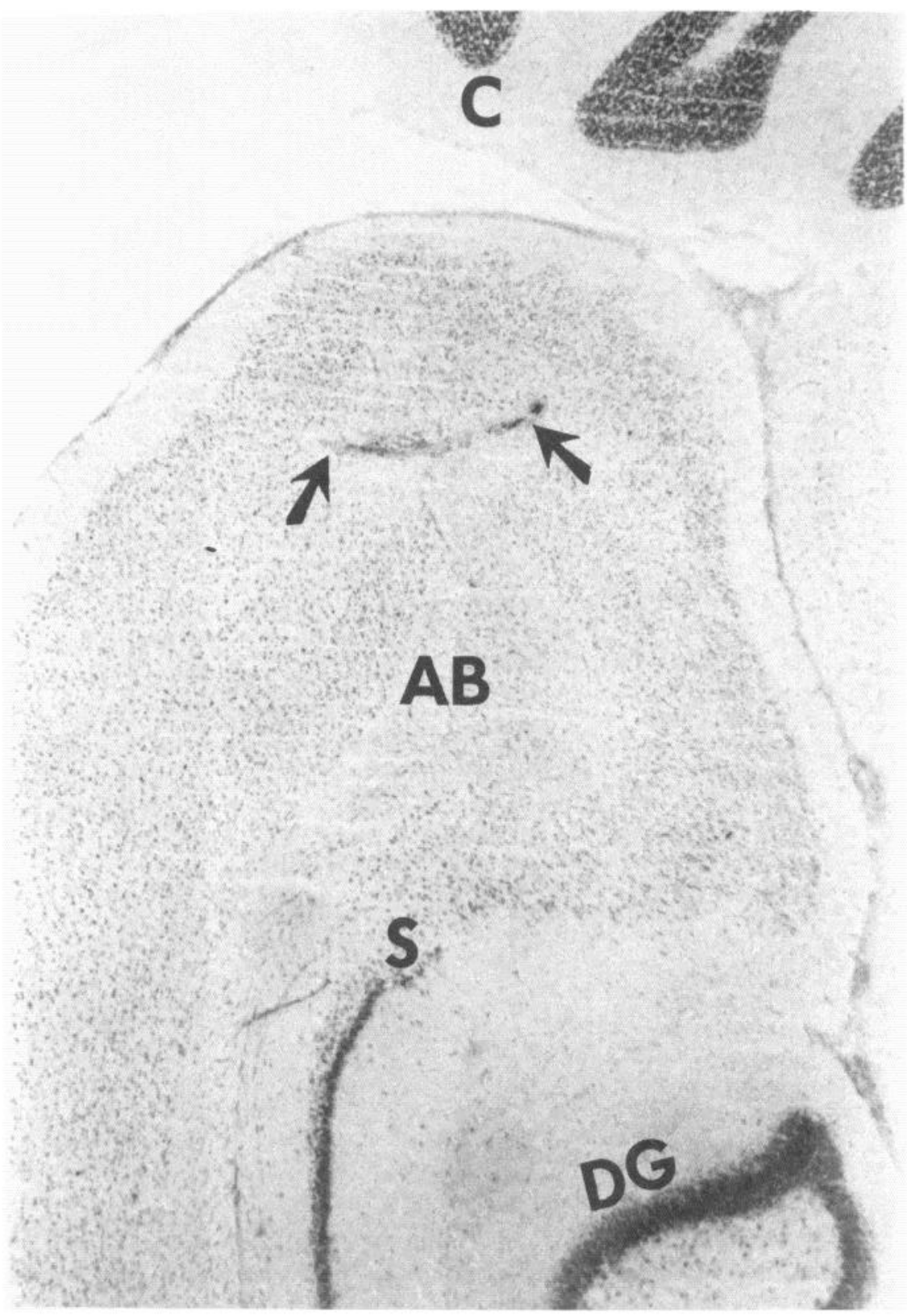

Figure 1. Nissl stain of horizontal section showing knife cut (arrows) in the entorhinal cortex posterior to the angular bundle $(A B)$. Other structures identified include cerebellum $(C)$ and the cell layers of the subiculum $(S)$, and the dentate gyrus $(D G)$. Magnification $\times 67$. 


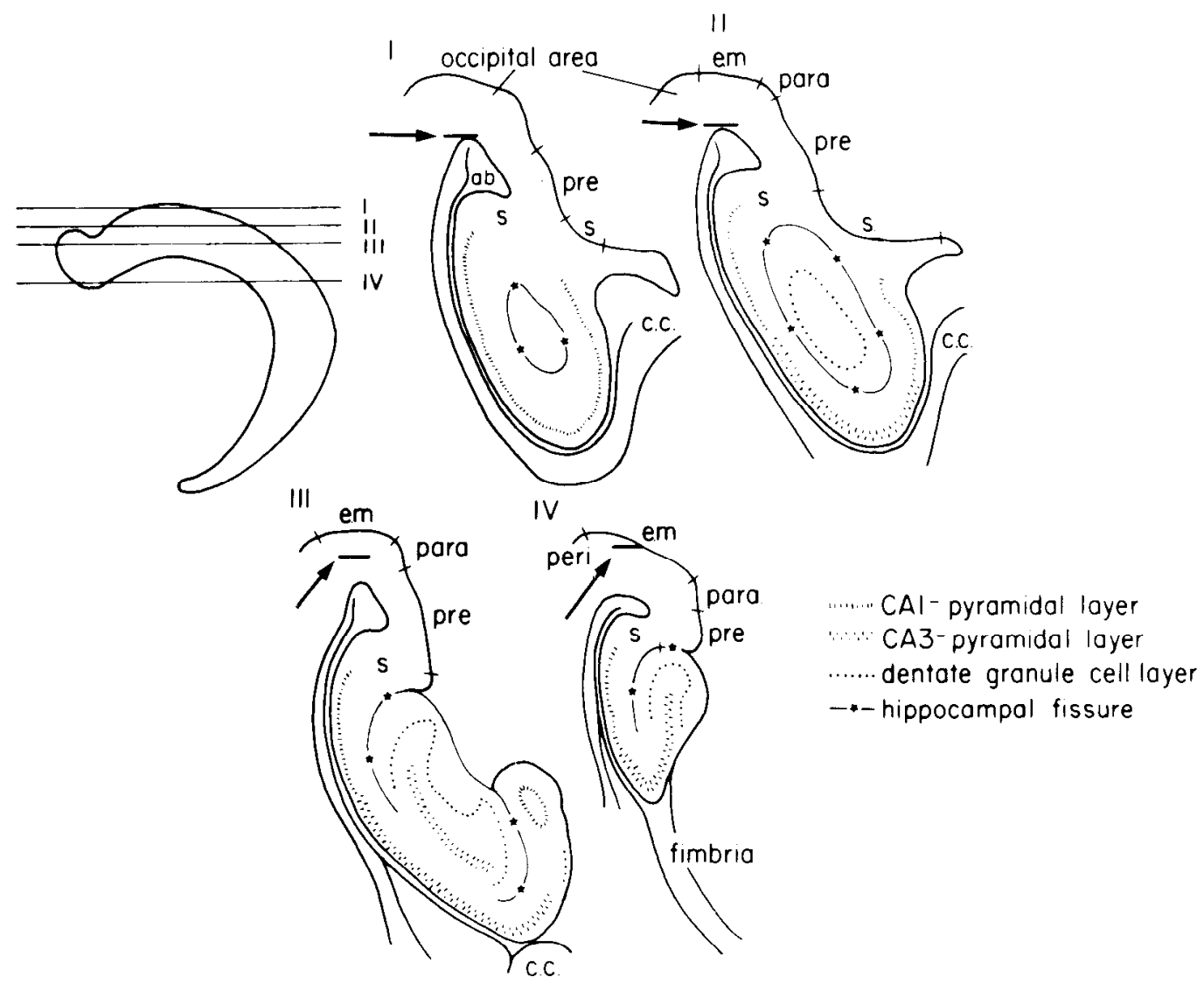

Figure 2. Schematic diagram of a representative knife cut (arrows) in the entorhinal cortex in serial horizontal sections. Top left, the levels of the sections in relation to the dorsoventral extent of the hippocampus are shown. The knife cut is increasingly posterior to the angular bundle in the deeper sections; knife cuts were not detectable below level IV. Structures identified include the angular bundle $(a b)$, subiculum $(s)$, medial entorhinal cortex (em), parasubiculum ( para), presubiculum ( pre), perirhinal cortex (peri), and corpus callosum (c.c.). This schematic diagram is modified from Figure 4 of Hjorth-Simonsen and Jeune (1972).

formation disclosed silver grain distributions equivalent to previous reports from this (Savage et al., 1983) and other (Kuhar and Yamamura, 1976) laboratories.

The optical density of silver grain deposition on the filn corresponding to the molecular layer of the infrapyramidal blade of dentate gyrus was measured using a Zeiss photometer attached to a Leitz Dialux microscope. Densitometric readings were taken using green-filtered incandescent light with a $\times 10$ objective. The photometer slit diameter was $1.0 \mathrm{~mm}$. Under these conditions the photometer sampled the optical density of a circular area of $1.13 \times 10^{4} \mu \mathrm{m}^{2}$. The diameter of the circular sample area was approximately $120 \mu \mathrm{m}$, corresponding to roughly half the distance across the molecular layer of the dentate gyrus. Eight absorbance readings were taken across the middle portion of the molecular layer of the infrapyramidal blade throughout the entire mediolateral extent (Fig. 3). These eight readings were averaged and represented a single sample. The infrapyramidal blades were measured on the left and right sides of each section. Four sections were analyzed for each animal. Thus, a total of eight samples was used to determine the mean and standard error of the optical density of the molecular layer of the infrapyramidal blade of the dentate gyrus for each animal.

The amount of $\left[{ }^{3} \mathrm{H}\right] \mathrm{QNB}$ specifically bound was determined by comparing the mean optical density of the sample to a standard curve. The standard curve was obtained with $16-\mu \mathrm{m}$ sections of frozen brain paste containing known amounts of $\left[{ }^{3} \mathrm{H}\right]$ formaldehyde. The sections were thaw mounted on slides which were exposed to film along with the sample sections. The mean absorbance of the film exposed to these standards was plotted against the corresponding counts per minute (data obtained previously by determining the radicactivity in solubilized brain paste sections using liquid scintillation spectroscopy. Standard curves were linear over a range of $50 \mathrm{cpm}$ (background) up to $10,000 \mathrm{cpm} / \mathrm{standard}$. Based on the standard curve, the mean optical density of each sample could be converted to counts per minute. Sample counts per minute data ranged from 4,900 to $7,000 \mathrm{cpm}$. Knowledge of the specific activity of the $\left[{ }^{3} \mathrm{H}\right] \mathrm{QNB}(33.1 \mathrm{Ci} / \mathrm{mmol}$, New England Nuclear, Boston, MA), the scintillation counter efficiency $(45 \%)$, and the photosampling area $\left(1.13 \times 10^{4} \mu \mathrm{m}^{2}\right)$ permitted conversion of the counts per minute data into femtomoles of $\left[{ }^{3} \mathrm{H}\right]$ bound per $10^{4} \mu \mathrm{m}^{2}$.

Statistics. Statistical comparisons of the kindling stimulation data and the specific $\left[{ }^{3} \mathrm{H}\right] \mathrm{QNB}$ binding data were performed with the Student's $t$ test, two tailed. A two-way analysis of variance was also employed for analysis of the binding data.

\section{Kesults}

Effect of entorhinal cortical knife cuts on kindling developmenl. Bilateral entorhinal cortical knife cuts (Figs. 1 and 2) suppressed the rate of development of amygdaloid kindling in four separate experiments. The pooled results of the four experiments disclosed that establishment of kindling required 25 \pm 3 (mean \pm SEM) stimulations in 14 control animals and 42 \pm 3 stimulations in 14 animals with entorhinal cortical knife cuts. This $72 \%$ increase was highly significant $(p<0.001$, Student's $t$ test). These data underestimate the suppressive effect of the lesion, since the kindling criterion had not been fulfilled in 6 of the 14 experimental animals after 50 stimulations. According to the protocol, these animals were arbitrarily assigned 50 as the number of stimulations required for kindling. Kindling was established in all control animals with fewer than 50 stimulations. There were no significant $(p>0.10)$ differences in the afterdischarge thresholds between the two groups (control, $711 \pm 61 \mu \mathrm{A}$; knife cut, $629 \pm 50 \mu \mathrm{a}$ ).

To determine whether knife cuts per se would retard the development of amygdaloid kindling, the effects of bilateral neocortical knife cuts on amygdaloid kindling were studied. No significant differences were found in the rate of kindling devel- 


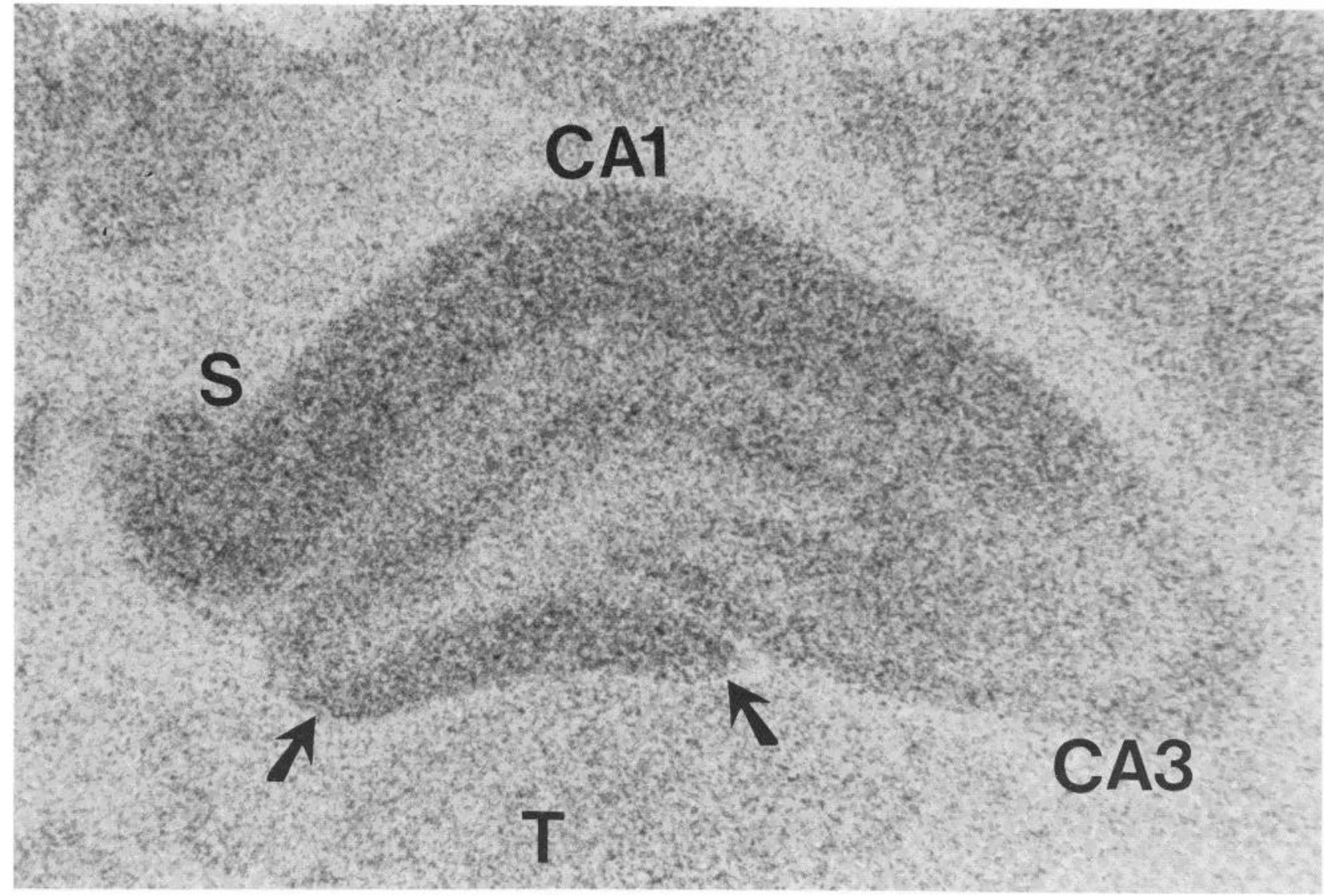

Figure 3. $\left[{ }^{3} \mathrm{H}\right] \mathrm{QNB}$ autoradiograph of hippocampal formation using ${ }^{3} \mathrm{H}$-sensitive Ultrofilm (LKB). This section represents total $\left[{ }^{3} \mathrm{H}\right] \mathrm{QNB}$ binding. The section representing nonspecific binding is not pictured because it was not readily differentiated from the background of the film. Densitometric measurements presented in Table I were taken from the molecular layer of the infrapyramidal blade of the dentate gyrus (arrows). Structures identified include hippocampal areas $(C A 3$ and $C A 1)$, subiculum $(S)$, and thalamus $(T)$. Magnification $\times 40$.

opment in 13 control $(24 \pm 2)$ and 11 lesioned $(22 \pm 3)$ animals. Thus, the presence of cortical knife cuts alone is not sufficient to retard amygdaloid kindling.

Effects of entorhinal cortical knife cuts on kindled seizureinduced decreases of $\left[{ }^{3} H\right] Q N B$ binding. To test the hypothesis that the entorhinal cortical knife cuts would prevent the kindled seizure-induced decline of muscarinic receptor number in fascia dentata, the following experiments were performed. Muscarinic receptors were measured in the infrapyramidal blade of fascia dentata from $\left[{ }^{3} \mathrm{H}\right] \mathrm{QNB}$ autoradiographs of coronal sections (approximate level A4110, Konig and Klippel, 1963) obtained from each of four groups: electrode-implanted, unstimulated controls $(n=3)$; kindled $(n=4)$; entorhinal cortical knife cuts without stimulations $(n=3)$; and kindled after bilateral entorhinal cortical knife cuts $(n=3)$ (Fig. 3, Table I). The kindled animals exhibited statistically significant $(p<$ 0.02 ) decreases $(22 \%)$ of $\left[{ }^{3} \mathrm{H}\right] \mathrm{QNB}$ binding in comparison to electrode-implanted, unstimulated controls. Entorhinal cortical knife cuts alone caused no significant alteration of $\left[{ }^{3} \mathrm{H}\right] \mathrm{QNB}$ binding in comparison to electrode-implanted, unstimulated controls. Kindled seizures induced after bilateral entorhinal cortical knife cuts caused no significant decline of $\left[{ }^{3} \mathrm{H}\right] \mathrm{QNB}$ binding in fascia dentata.

The absence of a decline of $\left[{ }^{3} \mathrm{H}\right] \mathrm{QNB}$ binding after the knife cuts was not simply due to the absence of behavioral or electrical seizure activity. Among the three animals kindled after entorhinal knife cuts, two reached kindling criterion after 44 stimulations. The third had exhibited two class 4 seizures by the 50th stimulation. The behavioral and afterdischarge fea-
TABLE I

Effect of bilateral entorhinal cortical knife cuts on the seizure-induced down regulation of $\left[{ }^{3} \mathrm{H}\right] Q N B$ binding in dentate gyrus

A two-way analysis of variance disclosed that the $\mathrm{F}$ ratios of the row variable, column variable, and interaction were all significant with $p$ values $<0.05$.

\begin{tabular}{lcc}
\hline & Unstimulated & Kindled \\
\hline Controls & $176 \pm 4^{a}$ & $141 \pm 8^{b}$ \\
$\begin{array}{l}\text { Entorhinal cortical knife } \\
\text { cuts }\end{array}$ & $174 \pm 4$ & $172 \pm 1$ \\
& $(3)$ & $(3)$ \\
\hline
\end{tabular}

${ }^{a}$ Values are mean \pm SEM femtomoles of $\left[{ }^{3} \mathrm{H}\right] \mathrm{QNB}$ specifically bound per $100 \mu \mathrm{m}^{2}$.

${ }^{b} p<0.02$ compared to either unstimulated control or kindled with entorhinal cortical knife cuts (two-tailed Student's $t$ test).

${ }^{c}$ Numbers in parentheses, number of animals.

tures of the seizures in these animals were similar to those of the unlesioned animals.

The reduction of $\left[{ }^{3} \mathrm{H}\right] \mathrm{QNB}$ binding observed in these experiments almost certainly reflects a reduction in the number of binding sites rather than an alteration of affinity. This seems likely because we previously found quantitatively similar reductions of binding in this model and demonstrated this to be due to decreased numbers of binding sites without alteration in affinity (Dasheiff et al., 1981). The presence of the decrease with concentrations of $\left[{ }^{3} \mathrm{H}\right] \mathrm{QNB}$ occupying approximately $90 \%$ of these binding sites further argues against an affinity change. 


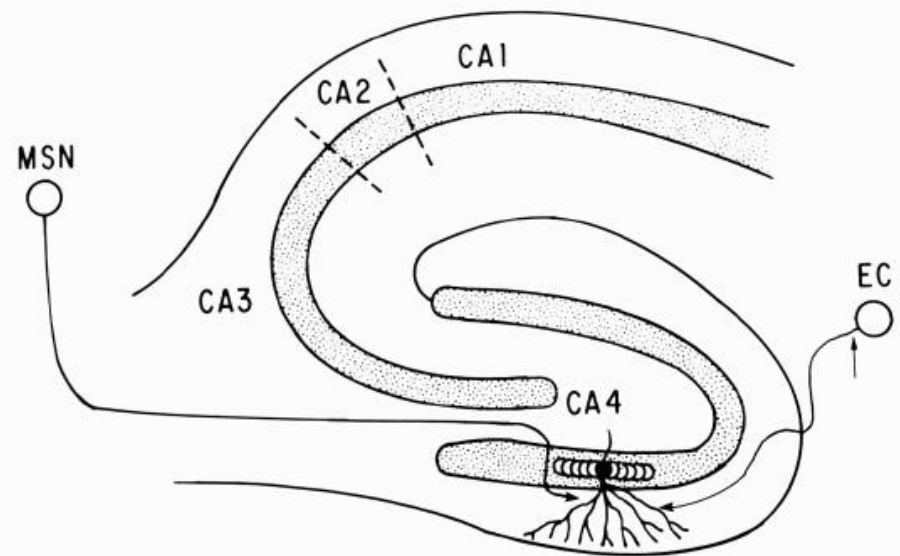

Figure 4. Schematic diagram of two afferents of dentate granule cells of the hippocampal formation. Cholinergic afferents arise from the medial septal nucleus $(M S N)$ and terminate on the somata and proximal dendrites of the granule cells (Chandler and Crutcher, 1983). The entorhinal cortical $(E C)$ afferents terminate more distally on the dendrites of the granule cells (Hjorth-Simonsen and Jeune, 1972). The arrow signifies the area of transection of the EC neurons. The subdivisions of Ammon's horn are designated (CA1, CA2, CA3, and CA4).

\section{Discussion}

Our principal findings are 2-fold: (1) bilateral knife cuts of entorhinal cortex but not of dorsal neocortex suppress the development of amygdaloid kindling; and (2) knife cuts of entorhinal cortex eliminate the seizure-induced decline in number of muscarinic receptors in dentate gyrus.

Speculation regarding mechanism and functional implication of decreases in muscarinic receptor number. Our previous studies of muscarinic receptors in this model demonstrated that repeated seizures, not kindling per se, are responsible for the decreased number of muscarinic receptors (Dasheiff et al., 1982). We also demonstrated that the muscarinic receptors in dentate gyrus reside principally, if not exclusively, in the dentate granule cells (Savage et al., 1983). The present studies confirm our previous work by demonstrating the significant reduction of $\left[{ }^{3} \mathrm{H}\right] \mathrm{QNB}$ binding in the molecular layer of dentate gyrus after kindled seizures.

We previously speculated that the mechanism responsible for the decreased numbers of muscarinic receptors was repeated depolarization of granule cells during the seizures (Dasheiff and McNamara, 1980). This speculation was based on the following observations: (1) the declines of receptor number in this model occur independently of the agonist, acetylcholine (Dasheiff and McNamara, 1980); (2) chemical depolarization of cultured muscle cells (in the absence of acetylcholine) caused reduction of nicotinic cholinergic receptor binding (Betz and Changeux, 1979); and (3) chemical depolarization of brain synaptosomes without acetylcholine causes a reduction of muscarinic receptor binding (Lugmani et al, 1979).

To begin to test this hypothesis, we transected the axons of the principal excitatory afferent to the dentate granule cells, namely, the projection from entorhinal cortex (Andersen et al., 1966), and demonstrated that the seizure-induced decline of muscarinic receptor number was no longer detectable. Our interpretation is that the knife cut reduced the repeated depolarization of dentate granule cells ordinarily mediated by the excitatory entorhinal afferents during the seizure. Since the entorhinal afferents are not cholinergic (Storm-Mathisen, 1974), this idea implies that the down regulation is mediated by a heterosynaptic mechanism. Thus, information communicated to the granule cells through entorhinal afferents may cause a reduction of their responsiveness to cholinergic affer- ents originating in the medial septal nucleus (Chandler and Crutcher, 1983) (Fig. 4).

Speculation regarding the role of the hippocampal formation in amygdaloid kindling. We previously suggested that the hippocampal formation facilitated the development of amygdaloid kindling (Dasheiff and McNamara, 1982). This suggestion was based on the finding that microinjection of colchicine into the dentate gyrus but not into neocortex retarded the development of amygdaloid kindling. Since intradentate colchicine virtually destroyed the granule cells of the entire hippocampal formation completely, we hypothesized that its effect on kindling development was due to removal of the granule cells from the hippocampal network, thereby reducing information transfer through this structure.

Our interpretation is that the present findings support this hypothesis. These lesions transect the entorhinal afferents to the hippocampal formation. This would probably impair transmission of seizure information through the network and thus interfere with the facilitatory effect of the intact hippocampal circuitry. We recognize that alternate interpretations exist. These effects could be due to neuronal rearrangements transpiring after the lesion (e.g., expansion of septal cholinergic or commissural-associational afferents into the denervated area of the granule cell dendrites) (Lynch and Cotman, 1975). We also cannot exclude the possibility that transection of entorhinal afferents of areas other than the hippocampus (Wyss, 1981) as well as CA3 efferents to the entorhinal cortex (Swanson and Cowan, 1977) may contribute to these effects.

Recent lesion and electrophysiological experiments provide additional evidence supporting a facilitatory role of the hippocampal formation in limbic kindling. Yoshida (1984) reported that electrolytic lesions of the hippocampal formation of kindled animals suppressed subsequent responses to electrical stimulation. We (G. L. King, R. Dingledine, J. L. Giacohino, and J. O. McNamara, submitted for publication) have found that hippocampal slices removed from kindled rats exhibit increased spontaneous burst firing of neurons in the CA3 region and decreased synaptic inhibition in the CA1 region in comparison to control rats; these abnormalities could combine to predispose the animal to seizure.

One unexpected finding is that the extent of retardation of kindling was greater ( $72 \%$ more stimulations required to kindle) after these knife cuts than after destruction of dentate granule cells (46\% more stimulations required to establish kindling) (Dasheiff and McNamara, 1982). This seems paradoxical because the colchicine destroyed essentially all dentate granule cells throughout both hippocampal formations. By contrast, the knife cuts resulted in transection of mainly medial entorhinal cortical afferents of the dorsal two-thirds of the hippocampal formation. The entire entorhinal cortical projection to the ventral third of the hippocampal formation was spared by these lesions. This raises the possibility that the entorhinal afferents of CA3 and CA1 pyramidal cells, transected by the knife cuts but probably spared by intradentate colchicine, constitute key components of the network subserving kindling development.

\section{References}

Andersen, P., B. Holmqvist, and P. E. Voorhoeve (1966) Entorhinal activation of dentate granule cells. Acta Physiol. Scand. 66: 448-460.

Betz, H., and J. P. Changeux (1979) Regulation of muscle acetylcholine receptor synthesis in vitro by cyclic nucleotide derivatives. Nature 278: 749-752.

Chandler, J. P., and K. A. Crutcher (1983) The septohippocampal projection in the rat: An electron microscopic horseradish peroxidase study. Neuroscience 10: 685-696.

Dasheiff, R. M., and J. O. McNamara (1980) Evidence for an agonist independent down-regulation of hippocampal muscarinic cholinergic receptors in kindling. Brain Res. 195: 345-353. 
Dasheiff, R. M., and J. O. McNamara (1982) Intradentate colchicine retards the development of amygdala kindling. Ann. Neurol. 11:347352.

Dasheiff, R. M., M. C. Byrne, V. Patrone, and J. O. McNamara (1981) Biochemical evidence of decreased muscarinic cholinergic neuronal communication following amygdala kindled seizures. Brain Res. 206 : 233-238.

Dasheiff, R. M., D. D. Savage, and J. O. McNamara (1982) Seizures down regulate muscarinic cholinergic receptors in rat hippocampal formation. Brain Res. 235: 327-334.

Fink, R. P., and L. Heimer (1967) Two methods for selective silver impregnation of degenerating axons and their synaptic endings in the central nervous system. Brain Res. 4: 369-374.

Goddard, G. V., D. C. McIntyre, and C. K. Leech (1969) A permanent change in brain function resulting from daily electrical stimulation. Exp. Neurol. 25: 295-330.

Hjorth-Simonsen, A., and B. Jeune (1972) Origin and termination of the hippocampal perforant path in the rat studied by silver impregnation. J. Comp. Neurol. 144: 215-232.

Konig, J., and R. A. Klippel (1963) The Rat Brain: A Stereotaxic Atlas, Williams \& Wilkins, Baltimore.

Kuhar, M. J., and H. I. Yamamura (1976) Localization of cholinergic muscarinic receptors in rat brain by light microscopic radioautography. Brain Res. 110: 229-243.

Lugmani, Y. A., H. F. Bradford, N. J. M. Birdsall, and E. C. Hulme (1979) Depolarisation induced changes in muscarinic cholinergic receptors in synaptosomes. Nature 277: 481-483.

Lynch, G., and C. W. Cotman (1975) The hippocampus as a model for studying anatomical plasticity in the adult brain. In The Hippocampus, R. L. Isaacson and K. H. Pribram, eds., pp. 123-154, Plenum Press, New York.

McNamara, J. O. (1978) Muscarinic cholinergic receptors participate in the kindling model of epilepsy. Brain Res. 154: 415-420.

Pellegrino, L. J., A. S. Pellegrino, and A. J. Cushman (1979) A Stereotaxic Atlas in the Rat Brain, Plenum Press, New York.

Racine, R. J. (1972) Modification of seizure activity by electrical stimulation. II. Motor seizure. Electroencephalogr. Clin. Neurophysiol. 32: 281-294.

Savage, D. D., R. M. Dashieff, and J. O. McNamara (1983) Kindled seizure-induced reduction of muscarinic cholinergic receptors in rat hippocampal formation: Evidence for localization to dentate granule cells. J. Comp. Neurol. 221: 106-112.

Steward, O. (1976) Topographic organization of the projections from the entorhinal area to the hippocampal formation of the rat. J. Comp. Neurol. 167: 285-314.

Storm-Mathisen, J. (1974) Choline acetyltransferase and acetylcholinesterase in fascia dentata following lesion of the entorhinal afferents. Brain Res. 80: 181-197.

Swanson, L. W., and W. M. Cowan (1977) An autoradiographic study of the organization of the efferent connections of the hippocampal formation in the rat. J. Comp. Neurol. 172: 49-84.

Wyss, J. M. (1981) An autoradiographic study of the efferent connections of the entorhinal cortex of the rat. J. Comp. Neurol. 199: 495517.

Yoshida, K. (1984) Influences of bilateral hippocampal lesions upon kindled amygdaloid convulsive seizure in rats. Physiol. Behav. 2: $123-126$. 